\title{
Clinical and Immunoserological Status 12 Weeks after Infection with COVID-19: Prospective Observational Study
}

\author{
Valiente De Santis L ${ }^{1,2}$, Pérez-Camacho I ${ }^{1,2 *}$, Sobrino B ${ }^{1,2}$, González GE ${ }^{3}$, Ruíz- \\ Mesa JD ${ }^{1,2}$, Plata $\mathrm{A}^{1,2}$, Márquez-Gómez $\mathrm{I}^{1,2}$, Fernández $\mathrm{MD}^{1,2}$, Castaño $\mathbf{M}^{1,2}$, \\ Oñate $\mathrm{F}^{1,2}$, Orihuela $\mathrm{F}^{1,2}$, Palop $\mathrm{B}^{4}$ and Reguera JM $\mathrm{M}^{1,2}$ \\ ${ }^{1}$ IBIMA, Department of Infectious Diseases, Spain \\ ${ }^{2}$ Regional University Hospital of Málaga, Department of Infectious Diseases, Spain \\ ${ }^{3}$ Regional University Hospital of Málaga, Department of Pneumology, Spain \\ ${ }^{4}$ Regional University Hospital of Málaga, Department of Microbiology, Spain
}

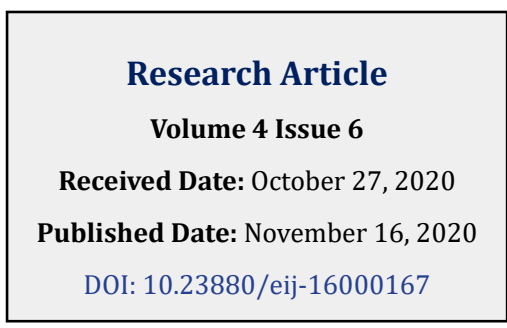

*Corresponding author: Inés Pérez-Camacho, IBIMA, Department of Infectious Diseases, Regional University Hospital of Málaga, Department of Infectious Diseases, Spain, Avenida Carlos Haya s/n, Tel: +34952291775; Email: inpercam@gmail.com

\section{Abstract}

Objectives: to undertake a multidisciplinary follow-up at 12 weeks after an acute episode of COVID-19 to assess the functional status, persistence of symptoms and immunoserological situation.

Methods: This prospective, observational, single-centre study included outpatients reviewed 12 weeks after an acute infection with SARS-CoV-2. The clinical evaluation included data about the acute episode and epidemiological and clinical variables. The patients were classified as symptomatic or asymptomatic depending on the persistence or otherwise of symptoms. All the patients underwent a full blood test and serology for SARS-CoV-2, as well as imaging tests and spirometry if needed.

Results: The mean age of the 108 patients was 55.5 (SD: 15.4) years and 27.8\% were health-care workers; $75.9 \%$ presented some type of symptoms, with dyspnoea being the most common. A D-dimer $>500 \mathrm{ng} / \mathrm{mL}$ was detected in 32 (31.4\%) patients. All the patients had antibodies against SARS-CoV-2. Being a health-care worker was associated with symptom persistence, with age $\geq 65$ years being a protective factor.

Conclusion: The persistence of symptoms in patents with COVID is usual 12 weeks after the acute episode, especially in patients $<65$ years and health-care workers. All our patients had developed antibodies by 12 weeks.

Keywords: Dyspnoea; COVID-19; Symptoms; Antibodies; Health-Care

Abbreviations: PCR: Polymerase Chain Reaction; AP: Alkaline Phosphatase; CT: Computerised Tomography; ICU: Intensive Care Unit; LDH: Lactate Dehydrogenase; CRP: C-Reactive Protein.

\section{Introduction}

Respiratory infection (COVID-19) caused by SARS-CoV-2 is characterized by asthenia, fever, dry cough, anosmia, arthromyalgia and dyspnoea, and less commonly by nasal congestion, headache, odynophagia, vomiting and diarrhoea. One week into the course of the disease some patients develop a very aggressive inflammatory response that can lead to respiratory failure secondary to adult respiratory distress, septic shock or coagulation disorders [1,2], which in turn can produce venous thromboembolism [3]. Reports also exist of involvement of the heart [4,5], nervous system [6], liver, kidney and skin [7] and eyes [8]. Whether these 


\section{Epidemiology International Journal}

lesions heal definitively or whether they leave persisting damage is unknown. Accordingly, it seems advisable to undertake monitoring and follow-up of patients who have had COVID-19 to determine any possible sequelae [9]. Few data are currently available about the immunoserological response in convalescing patients. Studies have suggested that the serological response with effect from 3 months after symptom onset could reach 100\% [10]. Nevertheless, little information exists about the duration of the presence of antibodies in COVID-19 patients. We therefore undertook a multidisciplinary follow-up of all COVID-19 patients seen at our hospital to determine their functional and immunoserological status, assess the presence of possible sequelae and evaluate their course.

\section{Material and Methods}

\section{Patients}

This prospective, observational, single-centre study included the first patients seen at the outpatients' office 12 weeks after acute SARS-CoV-2 infection diagnosed between 14 March and 15 April 2020 and who were discharged after hospital admission or after being seen at the emergency service of the Regional University Hospital in Malaga, Spain but who did not require admission, just home confinement during the acute phase. The patients were classified during the acute phase as a confirmed case (symptoms compatible with COVID-19 and positive result for the SARS-CoV-2 polymerase chain reaction (PCR) (Cobas 6800, Roche) in respiratory samples, or a suspected case (symptoms compatible with COVID-19 and negative PCR) [11]. All the patients were contacted by telephone 12 weeks after the acute phase to undertake a first assessment of their clinical status and make an office appointment.

\section{Clinical Assessment}

The clinical assessment was undertaken jointly by an infectious diseases specialist and a pulmonologist. The symptoms during the acute phase were classified as severe if the patient required hospital admission and mild if not. Comorbidity was assessed with the age-adjusted Charlson index. The patients were considered to have received specific treatment for COVID-19 if any of the following drugs were given for at least 24 hours: lopinavir/ritonavir, hydroxychloroquine or chloroquine (with or without azithromycin), tocilizumab, anakinra and steroids. A clinical history was taken of the current symptoms and all the patients underwent a physical examination. The patients were asked about the presence of fever (temperature $>37.5^{\circ} \mathrm{C}$ ), cough, dyspnoea, chest pain, palpitations, arthromyalgia, asthenia, diarrhoea, headache, anosmia, dysgeusia and psychological or cognitive changes (anxiety, mood disorders, insomnia, loss of memory, difficulty concentrating). Patients were considered to be symptomatic when they presented at least one of the symptoms and asymptomatic otherwise. SARSCoV-2 infection was ruled out in suspected cases with a negative COVID-19 PCR and negative results for IgM and IgG on the serological study at 12 weeks in the absence of immunosuppression. The patients were also classified according to whether they were health-care workers or not.

\section{Complementary Studies}

Prior to the office visit all the patients were shown to have a negative SARS-CoV-2 PCR in nasopharyngeal exudate. The following complementary tests were all undertaken at the same time: total leukocytes and lymphocytes, haematocrit, platelets, lymphocyte subsets, D-dimer, creatinine, aspartate aminotransferase alanine a min otransfera se, gamma glutamyltransferase, alkaline phosphatase (AP), lactate dehydrogenase (LDH), ferritin, interleukin 6 (IL-6), immunoglobulins IgA, IgM and IgG and C3 and C4 fractions plus a plain chest radiograph. Patients considered to require it also underwent respiratory function tests with diffusion testing, computerised tomography (CT) or CT angiography of the chest, echo-Doppler of the legs, ventilation/perfusion gammagraphy and echocardiogram.

\section{Serological Study}

The patients also underwent blood tests for IgG and IgM + IgA antibodies against SARS-CoV-2 with the kits COVID-19 VIRCLIA® IgG MONOTEST (Vircell) and COVID-19 VIRCLIA® IgM+IgA MONOTEST (Vircell) based on chemiluminescence (CLIA, ChemiLuminescent ImmunoAssay). The following antigens were used in these kits: the spike protein (S protein) and the nucleocapsid protein ( $\mathrm{N}$ protein). The use of both types of antigen gives the tests excellent sensitivity, in addition to that of the CLIA technique. For IgM a titre of 0.40.6 was considered indeterminate and a titre $>0.6$ as positive. For IgG a titre of 1.4-1.6 was considered indeterminate and a titre $>1.6$ as positive. In both cases lower titres were considered negative.

Lymphocyte subset analysis was with the BD Multitest 6-Color TBNK Reagent panel, which includes T lymphocytes (CD4, CD8, CD16 natural killer), B lymphocytes (naive, with and without isotope switching, transitional and plasma) and monocyte subsets (CD14, CD16 effector and regulatory).

\section{Posterior Follow-Up}

All the cases classified during the acute phase as suspected were reclassified as confirmed if they presented a positive SARS-CoV- 2 serology at 12 weeks. All the patients will be given office appointments each three months for a 


\section{Epidemiology International Journal}

minimum follow-up of one year.

\section{Statistical Study}

The continuous variables, expressed as the mean (standard deviation, SD), were compared with the MannWhitney $U$ test, and the categorical variables, expressed as number (\%), were compared with the $\chi^{2}$ or Fisher's exact tests. A P value $<0.05$ was considered significant. The statistical analysis was done with SPSS 22.0.0.0.

\section{Results}

Of the original 116 patients contacted $3(2.5 \%)$ refused to attend. Of the remaining $113,5(4.4 \%)$ were excluded as they proved not to be COVID cases. Table 1 shows the baseline characteristics of the patients during the acute episode. The mean age of the 108 patients was 55.5 (SD: $15.4)$ years, and $82(75.9 \%)$ had some sort of symptom at the time of office revision. Table 2 shows the symptoms, with a predominance of respiratory symptoms. Concerning the number of symptoms, $18.6 \%$ reported just one, $19.5 \%$ two and $39.8 \%$ three or more symptoms.

Table 1: Baseline characteristics of the patients during the acute episode.

\begin{tabular}{|c|c|c|c|c|}
\hline Characteristic & $\begin{array}{c}\text { Total } \\
N=108\end{array}$ & $\begin{array}{c}\text { Symptomatic } \\
\mathbf{N}=82 \\
\end{array}$ & $\begin{array}{c}\text { Asymptomatic } \\
N=26\end{array}$ & $\mathbf{p}$ \\
\hline $\begin{array}{l}\text { Sex, } N(\%) \\
\cdot \text { Female } \\
\cdot \text { Male }\end{array}$ & $\begin{array}{l}60(55.6) \\
48(44.4)\end{array}$ & $\begin{array}{l}47(57.3) \\
35(42.7)\end{array}$ & $\begin{array}{l}13(50) \\
13(50)\end{array}$ & NS \\
\hline Age $\geq 65$ years & $29(26.9)$ & $17(20.7)$ & $12(46.2)$ & 0.011 \\
\hline Health-care worker, $\mathrm{N}(\%)$ & $30(27.8)$ & $28(34.1)$ & $2(7.7)$ & 0.009 \\
\hline Charlson > 3, N (\%) & $21(19.4)$ & $11(13.4)$ & $10(38.5)$ & 0.005 \\
\hline $\begin{array}{c}\text { Acute symptoms, } \mathrm{N}(\%) \\
\cdot \text { Mild } \\
\cdot \text { Severe }\end{array}$ & $\begin{array}{l}64(59.3) \\
44(40.7)\end{array}$ & $\begin{array}{l}48(58.5) \\
34(41.5)\end{array}$ & $\begin{array}{l}16(61.5) \\
10(38.5)\end{array}$ & NS \\
\hline ICU during acute episode, $\mathrm{N}(\%)$ & $4(3.7)$ & $3(3.7)$ & $1(3.8)$ & NS \\
\hline Treatment during acute episode & $86(79.6)$ & $63(76.8)$ & $23(88.5)$ & NS \\
\hline \multicolumn{5}{|c|}{ Laboratory results during acute episode } \\
\hline $\begin{array}{c}\text { Lymphocytes during acute episode } * * *^{* *} \\
\cdot \text { Lymphopenia } \\
\cdot \text { No lymphopenia } \\
\end{array}$ & $\begin{array}{l}33(33) \\
67(67)\end{array}$ & $\begin{array}{l}24(32.4) \\
50(67.6)\end{array}$ & $\begin{array}{c}9(34.6) \\
17(65.4)\end{array}$ & NS \\
\hline $\begin{array}{c}\text { D-dimer during acute episode* } \\
\cdot \text { D-dimer }>500 \\
\cdot \text { D-dimer }<500\end{array}$ & $\begin{array}{l}71(77.2) \\
21(22.8)\end{array}$ & $\begin{array}{l}52(74.3) \\
18(25.7)\end{array}$ & $\begin{array}{c}19(86.4) \\
3(13.6)\end{array}$ & NS \\
\hline $\begin{array}{l}\text { Ferritin during acute episode* } \\
\cdot \text { Ferritin } \leq 1000 \mathrm{ng} / \mathrm{L} \\
\cdot \text { Ferritin }>1000 \mathrm{ng} / \mathrm{L}\end{array}$ & $\begin{array}{l}38(76) \\
12(24)\end{array}$ & $\begin{array}{c}29(74.3) \\
10(25.6)\end{array}$ & $\begin{array}{l}9(81.8) \\
2(18.2)\end{array}$ & NS \\
\hline $\begin{array}{c}\text { LDH during acute episode* } \\
. \mathrm{LDH} \leq 246 \mathrm{U} / \mathrm{L} \\
. \mathrm{LDH}>246 \mathrm{U} / \mathrm{L}\end{array}$ & $\begin{array}{l}20(35.1) \\
37(64.9)\end{array}$ & $\begin{array}{l}17(42.5) \\
23(57.5)\end{array}$ & $\begin{array}{c}3(17.6) \\
14(82.4)\end{array}$ & NS \\
\hline
\end{tabular}

*De los patients que estaba disponible

**Cifra de linfocitos menor de 900

ICU, intensive care unit; LDH, lactate dehydrogenase

A blood test was performed in 102 (94.4\%) of the 108 COVID-19 patients. Table 3 shows the main changes, highlighting an increase in D-dimer $>500 \mathrm{ng} / \mathrm{mL}$ in 32 (31.4\%) patients. No significant differences were seen according to the presence or absence of symptoms concerning imaging tests, $89(82.4 \%)$ patients had a control chest radiograph at 12 weeks after the acute episode. In 56 (62.9\%) this was normal, in $24(26.9 \%)$ the evolution of the images was favourable and in $9(10.1 \%)$ the radiological alterations seen during the acute phase had persisted or worsened. A chest CT 


\section{Epidemiology International Journal}

was done in 37 (41.5\%) patients; it was normal in 7 (18.9\%) and pathological in the rest: $24(64.9 \%)$ had ground-glass opacity, $3(8.1 \%)$ a pattern of pulmonary fibrosis, $2(5.4 \%)$ pulmonary thromboembolism and $1(2.7 \%)$ residual lobar infiltrate.

Table 2: Symptoms 12 weeks after the acute episode.

\begin{tabular}{|c|c|}
\hline Symptoms & N (\%) 82 (75.9) \\
\hline Dyspnoea & $60(55.6)$ \\
\hline Asthenia & $48(44.9)$ \\
\hline Cough & $28(25.9)$ \\
\hline Chest pain & $28(25.9)$ \\
\hline Palpitations & $24(22.2)$ \\
\hline Headache & $10(9.3)$ \\
\hline Anosmia & $10(9.3)$ \\
\hline Dysgeusia & $5(5.6)$ \\
\hline Fever & $4(3.7)$ \\
\hline Chills & $4(3.7)$ \\
\hline Arthromyalgia & $3(2.8)$ \\
\hline Hair loss & $3(2.8)$ \\
\hline Diarrhoea & $2(1.9)$ \\
\hline Psychological and cognitive & $18(16.7)$ \\
disorders: & $7(6.4)$ \\
- Sadnety & $7(6.4)$ \\
- Insomnia & $2(1.9)$ \\
- Loss of memory & $2(1.9)$ \\
Difficulty concentrating & $2(1.9)$ \\
\hline
\end{tabular}

Table 3: Main results of the laboratory studies.

\begin{tabular}{|c|c|}
\hline Parameters & N (\%) \\
\hline Leukopenia (leukocytes <4000) & $6(5.8)$ \\
\hline Lymphopenia (lymphocytes <900) & $7(6.8)$ \\
\hline CD4/CD8 ratio <1 & $6(5.8)$ \\
\hline D-dimer $>500 \mathrm{ng} / \mathrm{mL}$ & $32(31.3)$ \\
\hline $\mathrm{LDH}>246 \mathrm{U} / \mathrm{L}$ & $7(6.8)$ \\
\hline $\mathrm{CRP}>2.9 \mathrm{mg} / \mathrm{dL}$ & $25(24.5)$ \\
\hline Ferritin $>252 \mathrm{ng} / \mathrm{mL}$ & $9(8.8)$ \\
\hline IL-6 $>40 \mathrm{pg} / \mathrm{mL}$ & $4(3.9)$ \\
\hline IgM $<40 \mathrm{mg} / \mathrm{dL}$ & $6(5.8)$ \\
\hline IgG $<600 \mathrm{mg} / \mathrm{dL}$ & $11(10.7)$ \\
\hline
\end{tabular}

LDH, lactate dehydrogenase; CRP, high-sensitivity C-reactive protein
Spirometry was performed in 32 (29.6\%) patients. In $23(71.9 \%)$ the result was normal, $4(12.5 \%)$ had an obstructive pattern, $3(9.4 \%)$ a mixed pattern and in 2 $(6.3 \%)$ the alterations were interpreted as secondary to poor collaboration. None of the baseline characteristics was associated with radiological or respiratory function changes.

The serological test was not undertaken in $3(2.7 \%)$ of the 108 patients. Table 3 shows the serological response of the remaining 105 COVID-19 patients. All patients had a serological response (IgG in 98.1\%) and at 12 weeks 55\% were positive for both IgM and IgG antibodies (Table 4).

Table 4: Serological response.

\begin{tabular}{|c|c|c|c|c|}
\hline $\begin{array}{c}\text { Antibodies, N } \\
\text { (\%) }\end{array}$ & Total & Symptomatic & $\begin{array}{c}\text { Asymp- } \\
\text { tomatic }\end{array}$ & $\mathbf{p}$ \\
\hline IgM positive & $60(57.1)$ & $45(56.3)$ & $15(60)$ & NS \\
\hline IgM negative & $35(33.3)$ & $28(35.5)$ & $7(28)$ & NS \\
\hline $\begin{array}{c}\text { IgM } \\
\text { indeterminate }\end{array}$ & $10(9.5)$ & $7(8.8)$ & $3(12)$ & NS \\
\hline IgG positive & $103(98.1)$ & $79(98.8)$ & $24(96)$ & NS \\
\hline IgG negative & $2(9.1)$ & $1(1.3)$ & $1(4)$ & NS \\
\hline $\begin{array}{c}\text { IgM and IgG } \\
\text { positive }\end{array}$ & $58(55.5)$ & $44(55)$ & $14(56)$ & NS \\
\hline
\end{tabular}

Being a health-care worker was associated with symptom persistence ( $\mathrm{OR}=4.79$ [95\% CI $=1.02-22.38], \mathrm{p}=0.046)$, with age $\geq 65$ years being a protective factor $(\mathrm{OR}=0.33[95 \% \mathrm{CI}=$ 0.12-0.87], $\mathrm{p}=0.026$ ) (Table 5).

Table 5: Risk factors for persistence of symptoms.

\begin{tabular}{|c|c|c|}
\hline Variable & $\begin{array}{c}\text { OR multivariate } \\
\text { analysis (95\% CI) }\end{array}$ & $\mathbf{p}$ \\
\hline Age >65 years & $0.33(0.12-0.87)$ & 0.026 \\
\hline Health-care worker & $4.79(1.02-22.38)$ & 0.046 \\
\hline $\begin{array}{c}\text { Mild or severe acute } \\
\text { episode }\end{array}$ & - & 0.087 \\
\hline Charlson > 3 & - & 0.13 \\
\hline D-dimer $>500 \mathrm{ng} / \mathrm{mL}$ & - & 0.317 \\
\hline $\begin{array}{c}\text { Specific treatment for } \\
\text { COVID-19 }\end{array}$ & - & 0.435 \\
\hline
\end{tabular}

\section{Discussion}

Few studies examining the course of patients with COVID-19 have included data about possible sequelae 


\section{Epidemiology International Journal}

and the immunoserological response against SARS-CoV-2. In our study most of the infected patients $(75.9 \%)$ in our preliminary SARS-CoV-2 cohort continued to have symptoms 12 weeks after the acute episode. This coincides with the results reported by Carfi et al., who assessed the presence of residual symptoms in 143 patients after a mean of 60 days following the acute episode [12]; 87.4\% of the patients reported persistence of symptoms.

Dyspnoea was the predominant symptom in most of our patients. A retrospective study comprising 50 patients assessed one month after the acute episode found that over half presented worsened lung function, mostly consisting of restrictive and diffusion alterations, generally mild [13]. Likewise, the persistence of diffusion alterations seems more common in patients who have severe pneumonia during the acute episode [14]. In our series, the prevalence of alterations detected on spirometry was lower than in the previous series, though our series included more patients with a mild acute episode than the others.

Additionally, as spirometry in our cohort was determined by the persistence of symptoms, a lower percentage of patients underwent the test. Although most of the patients with radiological alterations during the acute phase evolved favorably, $37 \%$ still had some degree of persistence of symptoms. The chest CT in these patients confirmed the presence of radiological lesions, most frequently persistence of the ground-glass opacity. This is in contrast to the findings of Zhao YM, et al. [15] who assessed 55 patients three months after acute infection with SARS-CoV- 2 and found that $70 \%$ has persistence of radiological alterations. However, whereas in our series it was persistence of ground-glass opacity and crazy paving in their series it was interstitial thickening compatible with pulmonary fibrosis [15]. The three patients with fibrosis in our series had presented severe clinical symptoms, with one having bilateral pneumonia and requiring admission to the intensive care unit, which agrees with the literature [16]. Of note is the high number of patients who reported dyspnoea, sometimes with cough and chest pain, but who had no demonstrable respiratory function or radiological alterations. The association of these systemic symptoms together with asthenia and psychological disorders could constitute what has been called post-viral or post-covid chronic fatigue syndrome [17]. The presence of anxiety and depression has been reported with SARS [18] and they may persist beyond the duration of the bout. In our series, $16.7 \%$ of the patients experienced psychological or cognitive alterations after the acute episode of COVID-19, which is in concordance with the impact that other outbreaks have had for the mental health of the patients and the community in general [19]. Nine of our patients required psychiatric assessment. The most frequent symptoms after respiratory symptoms were neurological symptoms, occurring in about one in every 10 patients, mainly persistence of headache, anosmia and dysgeusia. The presence of these symptoms during the acute infection is common [6,20] and although most cases appear to resolve in less than 4 weeks [21], our results suggest that these alterations may persist in some patients for at least three months.

During the acute phase of SARS-CoV-2 there can be involvement of the myocardium, producing myocarditis. Whilst the prognosis for this appears favourable, we are unaware of the long-term consequences of this myocardial damage, and it may be part of the genesis of the palpitations and chest pain sometimes reported by patients at revision [22]. Another important cardiovascular aspect we have noted is the persistence in the rise in D-dimer in over $30 \%$ of the patients three months after the acute phase; one of our patients even showed pulmonary thromboembolism on the control CT. This all suggests the need to maintain the patient's ant coagulated for an indeterminate period [23]. Unfortunately, we are unable to provide a response to this as our study was not designed with this in mind.

Almost all our patients had a humoral immune response by three months after the acute episode. Furthermore, this serological response was independent of the severity of the acute symptoms and the symptoms at the time of revision. Between 2 and 6 weeks after diagnosis of COVID-19 most patients develop antibodies against SARS-CoV-2, as shown in the study by Lin L, et al. [24] that included 334 patients with COVID-19 confirmed by SARS-CoV-2 PCR. Specific IgM or IgG antibodies were detected in all the patients. It has been suggested that asymptomatic patients could seroconvert to a lesser extent than patients with severe symptoms and could even become negative during the convalescence [25]. However, we failed to see this as all our patients had detectable antibodies 3 months after the acute episode.

Subsequent follow-up of our patients will show the evolution of the immunoserological response. Care of patients with COVID-19 has an important impact on the health of health-care workers $[26,27]$. This impact has both physical and mental consequences [27]. A retrospective cohort study found that symptoms of infection by COVID-19 in health-care workers are mild or moderate in $91 \%$ of cases [28]. Nonetheless, our data show that health-care workers more often have residual symptoms that persist after the acute episode. It would, therefore, be recommendable to undertake an evolutionary follow-up of this group after SARS-CoV-2 infection. Moreover, health-care workers have a greater risk of post-traumatic stress, with the younger workers more often developing this condition [26]. In our study the patients $<65$ years had a greater risk of residual symptoms. 


\section{Epidemiology International Journal}

\section{Conclusion}

In conclusion, 12 weeks after the acute episode residual symptoms are common in patients with COVID, the most frequent being respiratory involvement. Healthcare workers and patients $<65$ years have a greater risk of presenting persistent symptoms after the acute episode. An increase in D-dimer suggests the possibility of a state of hypercoagulability persisting after the acute phase. All our patients had developed IgM or IgG antibodies against SARSCoV-2 by 12 weeks.

\section{References}

1. Wang D, Hu B, Hu C, Zhu F, Liu X, et al. (2020) Clinical characteristics of 138 hospitalized patients with 2019 novel coronavirus-infected pneumonia in Wuhan, China. JAMA 323(11): 1061-1069.

2. Huang C, Wang Y, Li X, Ren L, Zhao J, et al. (2020) Clinical features of patients infected with 2019 novel coronavirus in Wuhan, China. Lancet 395: 497-506.

3. Iba T, Levy JH, Levi M, Connors JM, Thachil J (2020) Coagulopathy of Coronavirus Disease 2019. Crit Care Med 48(9): 1358-1364.

4. Arentz M, Yim E, Klaff L, Lokhandwala S, Riedo FX (2020) Characteristics and outcomes of 21 critically ill patients with COVID-19 in Washington state. JAMA 14720: 323(16): 1612-1614.

5. Chen C, Zhou Y, Wang DW (2020) SARS-CoV-2: a potential novel etiology of fulminant myocarditis. Herz 45(3): 230-232.

6. Mao L, Wang M, Chen S, He Q, Chang J, et al. (2020) Neurological manifestations of hospitalized patients with COVID-19 in Wuhan, China: a retrospective case series study. SSRN Journal, pp: 1-26.

7. Xu XW, Wu XX, Jiang XG, Xu KJ, Ying LJ, et al. (2020) Clinical findings in a group of patients infected with the 2019 novel coronavirus (SARS-CoV-2) outside of Wuhan, China: retrospective case series. BMJ 368: 606.

8. Wu P, Duan F, Luo C, Liu Q, Qu X, et al. (2020) Characteristics of ocular findings of patients with coronavirus disease 2019 (COVID-19) in Hubei Province, China. JAMA Ophthalmol 138(5): 575-578.

9. Balachandar V, Mahalaxmi I, Subramaniam M, Kaavya J, Kumar NS, et al. (2020) Follow-up studies in COVID-19 recovered patients - is it mandatory?. Sci Total Environ 729: 139021.
10. Long QX, Liu BZ, Deng HJ, Wu GC, Deng K, et al. (2020) Antibody responses to SARS-CoV- 2 in patients with COVID-19. Nat Med 26(6): 845-848.

11. (2020) Estrategia De Detección Precoz, Vigilancia Y Control De Covid-19. Instituto de Salud Carlos III, pp: 1-29.

12. Carfi A, Bernabei R, Landi F (2020) Persistent Symptoms in Patients After Acute COVID-19. JAMA 324(6): 603605.

13. Frija Masson J, Debray MP, Gilbert M, François Xavier L, Travert F, et al. (2020) Functional characteristics of patients with SARS-CoV-2 pneumonia at 30 days post infection. Eur Respir J 56: 2001754.

14. Mo X, Jian W, Su Z, Chen M, Peng H, et al. (2020) Abnormal pulmonary function in COVID-19 patients at time of hospital discharge. Eur Respir J 55(6): 2001217.

15. Zhao YM, Shang YM, Song WB, Li QQ, Xie H, et al. (2020) Follow-up study of the pulmonary function and related physiological characteristics of COVID-19 survivors three months after recovery. E Clinical Medicine 25: 100463.

16. Fang Y, Zhou J, Ding X, Ling G, Yu S (2020) Pulmonary fibrosis in critical ill patients recovered from COVID-19 pneumonia: Preliminary experience. Am J Emerg Med.

17. Perrin R, Riste L, Hann M, Walther A, Mukherjee A, et al. (2020) Into the looking glass: Post- viral syndrome post COVID-19. Med Hypotheses 144: 10055.

18. Brooks SK, Webster RK, Smith LE, Woodland L, Wessely S, et al. (2020) The psychological impact of quarantine and how to reduce it: rapid review of the evidence. Lancet 395(10227): 912-920.

19. Wong LP, Hung CC, Alias H, Lee TS (2020) Anxiety symptoms and preventive measures during the COVID-19 outbreak in Taiwan. BMC Psychiatry 20(1): 376.

20. Chen X, Laurent S, Onur OA, Kleineberg NK, Fink GR, et al. (2020) A systematic review of neurological symptoms and complications of COVID-19. J Neurol.

21. Meini S, Suardi LR, Busoni M, Roberts AT, Fortini A (2020) Olfactory and gustatory dysfunctions in 100 patients hospitalized for COVID-19: sex differences and recovery time in real-life. Eur Arch Otorhinolaryngol 4: 1-5.

22. Mitrani RD, Dabas N, Goldberger JJ (2020) COVID-19 cardiac injury: Implications for long-term surveillance and outcomes in survivors. Heart Rhythm 17(11): 19841990. 


\section{Epidemiology International Journal}

23. Violi F, Pastori D, Cangemi R, Pignatelli P, Loffredo L (2020) Hypercoagulation and Antithrombotic Treatment in Coronavirus 2019: A New Challenge. Thromb Haemost $120(6)$ : 949-956.

24. Lin L, Luo S, Qin R, Yang M, Wang X, et al. (2020) Longterm infection of SARS-CoV-2 changed the body's immune status. Clin Immunol 218: 108524.

25. Long QX, Tang XJ, Shi QL, Li Q, Deng HJ, et al. (2020) Clinical and immunological assessment of asymptomatic SARS-CoV-2 infections. Nat Med 26: 1200-1204.
26. Carmassi C, Foghi C, Dell'Oste V, Cordone A, Bertelloni CA, et al. (2020) PTSD symptoms in healthcare workers facing the three coronavirus outbreaks: What can we expect after the COVID-19 pandemic. Psychiatry Res 292: 113312.

27. Shaukat N, Ali DM, Razzak J (2020) Physical and mental health impacts of COVID-19 on healthcare workers: a scoping review. Int J Emerg Med 13: 40.

28. García IS, López MJMA, Vicente AS, Abascal PL (2020) SARS-CoV-2 infection among healthcare workers in a hospital in Madrid, Spain. J Hosp Infect 106(2): 357-363. 